self-respect or the respect of those who benefit by it. The phrase he coins and uses, " if the people could be got into medical clubs," shows the view he takes of the movement. But the working man in these days is not a log to be shoved and shunted about and patronised. His intelligence has been aroused and is still at work. By combination he can assert himself and improve his own condition. If those who, by experience or education, can help him or direct him to do so, it is good work done. A letter published in the Birmingham Daily Post explains that those alluded to by Alderman Stanton as riding in their carriages have risen in the world and ceased to be members of the Coventry Provident Dispensary, but have entered into a private arrangement to be supplied with drugs from it.

$$
\text { I am, Sirs, yours faithfully, }
$$

Fred. ToWnsend, M.P.

The Little Cloisters, Westminster Abbey, S.W., May 19th, 1833.

** We are sorry if there was anything in our notice of Mr. Townsend's paper to justify him in separating us from the "enlightened and wide-minded" medical men with whom it is his privilege to associate. We assure him that that is the class of medical men whom we most affect and humbly try to represent. We fear Mr. Townsend found it more easy to criticise our supposed "spirit" than to refute our figures and facts. Does he maintain or not that $£ 40$ a year is a rate of remuneration to sustain, much less to stimulate, "enlightened and wide-minded men," or that for such sums dispensaries are likely to get the best service? We are not of those who would "shove" the British workman into any institution. But we know good British workmen that pay their medical men reasonable sums, and who have sense enough to realise that they get due value for it. We have no objection to the mutual assurance principle, but those who use it should recognise the value of medical education and work. The explanation by the writer in the Birmingham Daily Post of those members of the Coventry Provident Dispensary who ride in carriages is not entirely satisfactory.-ED. L.

\section{"CLINICAL USES OF RARE DISEASES."} To the Editors of THE LANCET.

SIRS,-In his oration on the above subject published in your last issue, $\mathrm{Mr}$ Hutchinson enunciates a very important principle. Any given disease, says he, may vary in its intensity or deoree of development, and an individual may suffer from any degree or intensity of a disease from the barest touch of it to the fullest development. Mr. Hutchinson tells us more than this; but I wish to refer to the above statemrnt only, my object being to fix the attention of the profession as widely and deeply as possible on an important and not generally recognised truth. This end will, I think, be best served by adding, from my own experience, to $\mathrm{Mr}$. Hutchinson's illustrative examples.

1. I frequently see cases of anæmia with slight pigmentation, which I believe to be ill-developed forms of Addison's disease. 2. I am acquainted with a gentleman whose opinion of his own powers is so extravagant that I regard him as the victim of general paralysis of the insane. He has not altered in this respect during the last thirty years, and he is regarded hy everyone as a perfectly sane person. 3. A gentleman of high professional repute is, in my opinion, suffering from "paralysis agitans," and, paradoxical as it may seem, I attribute his professional success in some measure to his disease; it makes him slow and cautious, and prevents him from rushing at wild conclusions. I found my diagnosis on nis utterance chiefly, but also on his facial expression and the general stiffiness of his movements. Like myxodema, paralysis agitans is, I believe, in its ill-developed forms, a common complaint. 4. I personally sometimes suffer from slight pain in the left temple, with swelling of the temporal artery. I have little doubt that this is an ill-developed form of negrim-a "baby megrim," so to speak; and in reference to this disorder $I$ recall the case (described by Dr. Clifford Allbutt) of a patient who suffered from periodic megrim with vomiting, but who in course of time lost all the symptoms save the vomiting, which recurred at the wonted times. In like manner vomiting may, according to Dr. Allbutt, become the "limb or remnant" of a gastralgia.
Now, without a proper history of such cases, how could we possibly form a correct diagnosis?

May, 1889.

I am, Sirs, yours faithfully,

\section{PUNCTURE OF THE ABDOMEN FOR TYMPANITES.}

To the Editors of THE LANCET.

Sirs,-Haring observed recently cases of tympanites reported in THE LANCET in which it was necessary to puncture the intestine with a trocar before the patient was relieved, I beg to state that in one case which occurred in my practice a short time ago relief was instantly obtained by the patient being placed in the knee-elbow position after other means had completely failed. This simple device is worthy of a trial before having recourse to more severe measures.

Rotherham, May 21st, 1889.

I am, Sirs, yours truly,

\section{MANCHESTER.}

(From oUr OWN CoRrespondent.)

WM. OXLEY.

\section{The Assizes.}

A CASE of some medical interest came on for trial in the civil court during the recent assizes. The plaintiff had had a house built, and sued the builder thereof for defective work in putting in the drains, whereby it was alleged that he himself, his wife, and children contracted diphtheria and scarlet fever. The evidence clearly proved that the drains were in a bad condition, and, as stated by the medical man in attendance, whose opinion was supported by Dr. Dreschfeld, the diphtheria was in all probability the result of this defective drain, and possibly also had something to do with the children's attack of scarlatina. Unfortunately, as so often happens, conflicting medical evidence was forthcoming on the other side. Another member of the Infirmary staff gave it as his opinion that the drains were not the cause of the illness. The moral of the case would seem to be that more efficient supervision by the authorities is necessary over the erection of new houses. Here was a new house, built less than two years ago, with drains in such a state as to render the dwelling unsafe to live in. The jury considered that the illness had not been with certainty traced to the drains, and only allowed plaintiff the money spent for putting them in order, ignoring his claim for damages on account of his family's illness.

\section{Artisans' Dwellings.}

The members of the City Council almost unanimously accepted the resolution brought before them at the last meeting, empowering the Unhealthy Dwellings Committee to go on with its work of demolishing unhealthy property, and also authorising them to prepare plans or bring forward a scheme for the erection of artisans' dwellings to take the place of some of the unhealthy ones abolished. If this movement be carried out steadily and sufficiently, an important step will be taken to secure some diminution of our still scandalously high death-rate. Measles, scarlet fever, and typhoid have been unduly prevalent in the city lately. A hundred deaths from measles were registered during the past four weeks, and forty cases of typhold fever and upwards of a hundred and twenty cases of scarlatina reported during the same period.

Officer of Health to Salford.

In place of Dr. Tatham, the Salford Town Council has appointed Mr. C. E. Paget as medical officer of health. Mr. Paget is a son of Sir George Paget of Cambridge, and has for some few years held a similar post to a rural district in Westmoreland. His name is well known in connexion with school sanatoria, to wbich he has given much attention. He will find ample scope in Salford for work in endeavouring to improve the health of the population, many of whom are living under conditions utterly incompatible with health and vigour, or even decency and morality. A "Working Men's Sanitary Association" has just been formed, with a view to discovering and bringing forcibly to the attention of the authorities the worst insanitary conditions, and stimulating them to more vigorous action. The inquiry lately held by the Local Government Board respecting the proposed 